\section{Employee Grief, Workplace Culture, and Implications for Worker Productivity and Psychopathology}

\author{
Frank Eyetsemitan* \\ Roger Williams University, Bristol, USA
}

*Corresponding author: Frank Eyetsemitan

\section{feyetsemitan@rwu.edu}

Professor of Psychology, Roger Williams University, Bristol, RI 02809, USA.

Tel: 401-254-3500

\section{Citation: Eyetsemitan F (2017)}

Employee Grief, Workplace Culture, and Implications for Worker Productivity and Psychopathology. Acta Psychopathol Vol. 3 No. 4: 42.

\section{Introduction}

With more people staying longer in the workforce and not being able to retire, the issue of workplace bereavement now has become an important topic that needs careful attention. In the USA, the population is growing older and replacing older workers is becoming difficult because of a replacement gap created by a shrinking pool of younger workers.

In the case of workplace bereavement, in general older workers are likely to experience a different type of loss than younger workers. In Cartensen's socioemotional selectivity theory [1,2], unlike younger people older people view time are limited and therefore tend to devote more time to pursuing fewer and deeper relationship, especially with family members.

Many organizations lack a coherent bereavement policy and in some cases none exists. Those that have bereavement policies allow their bereaved workers to take only a few paid days off work for funerals and resume full-blown work thereafter. However, if not handled properly bereavement could affect worker performance resulting in workplace accidents and bad decisions [3]. McClellan [4] noted that workplace bereavement experience cost organizations billions of dollars. For some bereaved employees, however, resuming full flown responsibilities after a few days off may be a welcome distraction, but this could lead to delayed or complicated grief reactions. According to several studies bereavement is a risk factor for mental health problems, including depression and major depressive incidents [5-8].

Other studies have implicated bereavement in heart diseases, accidents, suicide, and cirrhosis of the liver $[7,9]$.

Unfortunately, as earlier mentioned several organizations lack workplace bereavement policies and leave whatever decisions on bereavement to the discretion of line managers. In reporting a survey by the Irish Hospice Foundation of 34 Irish organizations, McGuinness [10] noted that only four organizations had any kind of formal written policy. Yet all had experienced worker bereavement within the last 12 months. 


\section{The Type of Attachment Formed with the Deceased might have Implications for Worker Productivity and Psychopathology}

\section{Attachment types}

Weiss [11] noted two types of attachment - "Relationship of Community" and "Relationship of Attachment." The relationship of community involves friends, colleagues and adult siblings in different households, and the grief is less intense and doesn't produce as severe and persistent distress. Whereas, Relationship of attachment would include parents, children and spouses and in such cases, the grief is usually severe-producing persistent distress in the bereaved. Carstensen [1] suggested that older adults are likely to experience the Relationship of Attachment loss more than younger people because they trade quantity for quality in relationships.

\section{Exploratory survey}

An exploratory survey questionnaire was administered to respondents who had experienced bereavement while working. 145 volunteered responded to the survey questionnaire. Their ages ranged from 18-65 years with an average age of 30.95 years and they were mostly females (67\%). Thirty-five respondents were forty and above, while 109 respondents were thirty-nine years and under. The basis for this dichotomy is because the US Age Discrimination Act of 1967 considers 40 years and above as old and for workplace discrimination based on age [12]. All the respondents were employed in organizations based in southern Illinois of the USA.

\section{Measure}

In addition to providing demographics of age and sex, the respondents were made to answer: 1 ) If the deceased was a parent, child, pet, relative, friend or someone else (to determine attachment type) (scaled from one to five, with parent being 1 and friend or someone else being 5); 2) The strength of the respondent's emotional attachment to the bereaved (measured on a 1-5 scale; with 1 being very strong attachment and 5 very weak attachment); 3) If respondents attended the funeral of the deceased (indicating Yes/No with Yes=1 and No=2); 4) The number of paid days allowed off work by employers for funerals and bereavement (indicating 1, 2, 3, 4, 5 or Other days); and 5) If after the paid time allowed off work respondents resumed fullblown normal responsibilities (indicationg Yes/No, with Yes=1 and $\mathrm{No}=2$ ).

\section{Procedure}

Participants were approached outside of their work places (in homes, bowling alleys, college dormitories, and charity organizations) by a student research assistant. Participants must have experienced bereavement while working and were told to not respond to any item they felt uncomfortable with, or to the entire questionnaire. There was a $100 \%$ return rate.
The results indicated a significant difference between workers who were 40 years and above and participants who were 39 years and below on type of loss experienced $(M=2.60 ; S D=2.03$ vs. $M=4.24 ; S D=1.36 ; F=25.592 ; P=0.000$ ). Workers 40 years and above mostly reported parents and children (relationship of attachment loss) whereas participants 39 years and under mostly reported relatives and friends (relationship of community loss). Workers 40 years and above indicated a stronger emotional attachment to the deceased than workers 39 years and under $(M=1.29 ; S D=0.67$ vs. $M=1.62 ; S D=0.89 ; F=7.349 ; P=0.008)$. For both groups, however, there was no significant difference in the number of paid days given off work $(M=3.59$; $S D=1.35$ vs. $\mathrm{M}=2.51 ; \mathrm{SD}=1.36 ; \mathrm{F}=0.019, \mathrm{P}=0.891$ ); and in resuming full-blown responsibilities on return to work ( $M=1.20 ; S D=0.41$ vs. $M=1.13$, $\mathrm{SD}=0.41 ; \mathrm{F}=1.969 ; \mathrm{P}=0.163$ ).

Workers 40 years and above reported attending funerals (broadly defined) more than workers 39 years and under $(M=1.00$; $S D=0.00$ vs. $M=1.07 ; S D=0.26 ; F=12.897 ; P=0.000$ ). (It should be noted that funerals could take a variety of forms both personally and culturally to include viewing, wake, spreading of ashes, etc.).

\section{Discussion and Conclusion}

The workers 40 years and above reported stronger emotional ties to the deceased than the younger workers. They also attended funerals more than the younger workers, perhaps a reflection of the type of attachment they formed with the deceased. However, there was no significant difference in paid time given off work and in assuming normal responsibilities upon return to work, irrespective of attachments formed to the deceased. It appears that employers did not seem to recognize differences in attachment types-which could have implications for worker productivity and psychopathology $[5-8,13]$.

\section{Future Research}

- A questionnaire and/or an archival study of pre-and postworkplace performances of bereaved employees with "attachment of relationship" type of loss.

- Based on (a) above, if need be evaluate possible assistance that bereaved employees with attachment of relationship loss might require. Such assistance could include a mandatory referral to an Employee Assistance Program (EAP) for counseling.

- It is important that future studies also distinguish between losses experienced that were expected and not expected. Expected losses may be prepared for (even though grieved) whereas unexpectedly losses may not be prepared for (and therefore more traumatic).

- In general, if not handled properly grief could have implications for worker productivity and psychopathology. As older people increasingly remain in the workforce, the "relationship of attachment" type of loss is more likely to be experienced and if not handled properly, with likely implications for worker productivity and psychopathology. 


\section{References}

1 Carstensen L (1995) Evidence for a life-span theory of socioemotional selectivity. Curr Dir Psychol Sci 4: 151-156.

2 Carstensen LL, Mikels JA, Mather M (2006) Aging and the intersection of cognition, motivation and emotion. Curr Dir Psychol Sci 14: 117-121.

3 Hazen MA (2009) Recognizing and responding to workplace grief. Organ Dyn 38: 290-296.

4 McClellan K (1985) The changing nature of EAP practice. Pers Adm 30: 29-37.

5 Jacobs S, Hansen F, Kasl, Ostfeld A, Berkman L, et al. (1990) Anxiety disorders in acute bereavement: risk and risk factors. J Clin Psychiatry 51: 269-274.

6 Pasternak RE, Reynolds CF, Frank E, Miller D, Houck PR, et al. (1993) The temporal course of depressive symptoms and grief intensity in late-life spousal bereavement. Depression 1: 457-459.
7 Stroebe W, Stroebe MS (1993) Determinants of adjustment to bereavement in younger widows and widowers. In: Streobe MS, Stroebe W, Hansson RO (eds.) Handbook of bereavement: Theory, research, and interventions.

8 Zisook S, Shuchter SR, Sledge PA, Paulus M, Judd L, et al. (1994) The spectrum of depressive phenomena after spousal bereavement. J Clin Psychiatry 55: 29-36.

9 Soulsby LK, Bennett KM (2015) Widowhood in late life. Encyclopedia of Geropsychology pp: 1-8.

10 McGuinness B (2009) Grief in the workplace. Bereavement Care 28: 2-8.

11 Weiss RS (1988) Loss and recovery. J Soc Iss 44: 37-52.

12 Age Discrimination in Employment Act (1967) Public Law No. 90-202, 81 Stat 602

13 http://www.turner-white.com/pdf/brm_Psy_pre8_1.pdf 